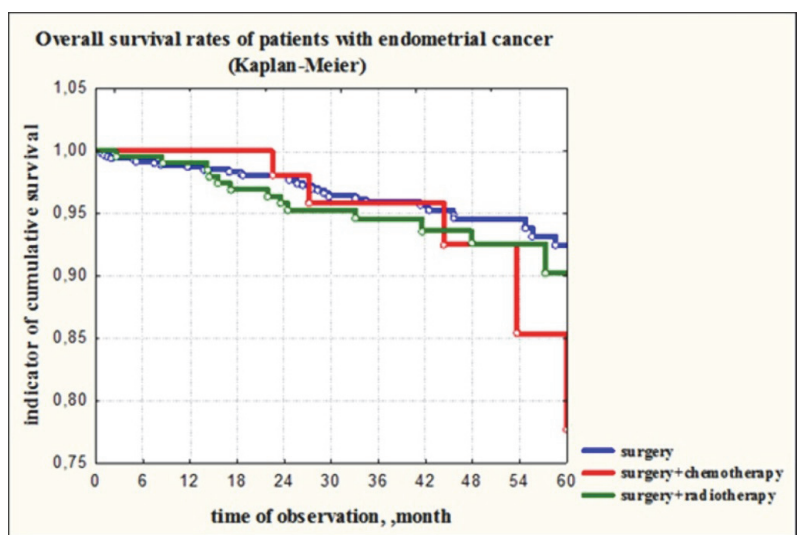

Abstract EPV098/\#177 Figure 1 Comparison of survival depending on the method of treatment in different groups of patients

National Cancer Institute from 2015 to 2020. Although threequarters received adjuvant treatment, recurrences occurred on average during the first three years.

Methods To evaluate the survival of patients with endometrioid stage I endometrial cancer depending on the type of treatment or their combination. The following statistical methods were used: standard descriptive and parametric. Survival of patients was analyzed by Kaplan-Meyer method. P values of $<0.05$ were considered significant.

Results Overall recurrence-free survival was $92.58 \pm 7.38 \%$ with a median non-recurrence survival of $34.3 \pm 14.7$ months. A total of 68 relapses were detected - 7.02\%. The median time from hysterectomy to the first recurrence, local and regional, was 6-18 months, respectively, and 24-36 months after combination treatment. The best survival was in the group of patients who received both surgical and chemotherapeutic treatment - averages of 59.5 months, and the worst after surgery - an average of 26.8 months ( $\mathrm{X}^{2}=1,031417$, $\mathrm{p}=0,59708)$ (See figure 1).

Conclusions Hysterectomy shows the most common recurrences of loco-regional, and the combination of surgical treatment with radiation therapy - increases the frequency of distant metastases. Surgical treatment with radiation or chemotherapy leads to improve recurrence-free survival.

\section{EPV099/\#179 ROBOTIC-ASSISTED SURGERY FOR ENDOMETRIAL CANCER IN MORBIDLY AND EXTREMELY MORBIDLY OBESE PATIENTS}

C Lechartier*, J Bernard, MC Renaud, M Plante. Hotel Dieu de Quebec, Gynecology Oncology, Quebec, Canada

\subsection{6/ijgc-2021-IGCS.169}

Objectives We sought to evaluate the outcome of roboticassisted surgery for endometrial cancer in morbidly obese (MO) and extremely morbidly obese (EMO) patients.

Methods We retrospectively reviewed all robotic gynecologic oncologic surgeries performed for endometrial cancer, in women with a BMI $\geq 40 \mathrm{~kg} / \mathrm{m} 2$, from 2012 to 2017 in our center. Patients were divided into two groups (MO: $40-49 \mathrm{~kg} /$ $\mathrm{m} 2$, EMO: $\geq 50 \mathrm{~kg} / \mathrm{m} 2$ ). Complications and outcome were compared. Fisher's test, t-test and Kaplan-Meier were used for statistical analyses.

Results Eighty-seven women were included: 64 (74\%) MO and 23 (26\%) EMO. The main histology was endometrioid adenocarcinoma (77\% of MO and $61 \%$ of EMO) and endometrial intraepithelial neoplasia (19\% of $\mathrm{MO}$ and $35 \%$ of EMO). The median blood loss was $100 \mathrm{~mL}$ in $\mathrm{MO}$ and $75 \mathrm{ml}$ in EMO $(p=N S)$. The median length of stay was one day for each group (range: 0-11). Two EMO (9\%) and none of the MO patients required conversion to laparotomy due to poor surgical field exposure $(p=0,067)$. Overall, 5 MO patients (8\%) and 5 EMO (22\%) had a surgical complication $(p=0,12)$, but only 3 patients ( $1 \mathrm{MO}$ and $2 \mathrm{EMO})$ required re-hospitalization within 30 days. The median follow-up was 47,7 months (range: 1,43-93,6). Recurrence occurred in $9 \%$ in each group, with no difference in recurrence-free survival $(p=0,96)$. Only one MO patient died of cancer recurrence.

Conclusions The robotic-assisted surgery for endometrial cancer in morbidly obese patients is a safe and feasible procedure. The morbidly obese and extreme morbidly obese patients appear to have similar oncologic outcome, length of hospital stay, blood loss and low surgical complications.

\section{EPV100/\#181 UTERINE CARCINOSARCOMA: A MULTICENTRE REVIEW OF TREATMENT AND OUTCOMES OVER 26 YEARS}

${ }^{1} \mathrm{C}$ Yim*, ${ }^{2} \mathrm{~S}-\mathrm{E}$ Yao, ${ }^{3}$ J Phung, ${ }^{4} \mathrm{M}$ Davies-Tuck, ${ }^{2} \mathrm{~T}$ Manolitsas, ${ }^{2} \mathrm{~J}$ Mcneilage, ${ }^{2} \mathrm{~K}$ Reid, ${ }^{5} \mathrm{O}$ Mcnally, ${ }^{6} \mathrm{R}$ Rome, ${ }^{2} \mathrm{~T}$ Jobling. ${ }^{1}$ Royal Women's Hospital, Gynaecologic Cancer Centre, Randwick, Australia; 'Monash Health, Gynaeoncology Unit, Moorabbin, Australia; ${ }^{3}$ University of Newcastle, School of Medicine and Public Health, Newcastle University, Australia; ${ }^{4}$ Hudson Institute of Medical Research, Epidemiology and Clinical Trials, Clayton, Australia; ${ }^{5}$ Royal Women's Hospital, Gynaeoncology Unit, Parkville, Australia; ${ }^{6}$ Epworth Healthcare, Epworth Freemasons Hospital, East Melbourne, Australia

\subsection{6/ijgc-2021-IGCS. 170}

Objectives Uterine carcinosarcoma (UCS) is a rare neoplasm with a poor prognosis and a paucity of evidence on treatment. The objective was to review the characteristics, treatment and outcomes of UCS cases across two gynaeoncology units and five private gynaeoncology practices in Melbourne.

Methods UCS cases were identified from hysterectomy pathology records between 1994 and 2020 inclusive. Patient characteristics, histopathological stage, adjuvant therapy, recurrence and survival status were extracted from patient records.

Results 208 cases of UCS were identified. The overall recurrence rate was $26.0 \%$ and the overall death rate was $60.1 \%$. Increasing age at diagnosis was associated with an increased risk of death (adjusted OR 1.04, 95\% CI 1.01-1.08, $\mathrm{p}=0.019$ ). Risk of death was highest in Stage III disease (adjusted OR 4.37, 95\% CI 1.67-11.40). Recurrence was a strong determinant of death, with an adjusted OR of 7.58 $(\mathrm{p}<0.001)$.

Conclusions In this relatively large homogenous cohort of UCS cases, significant predictors for survival included age at diagnosis, stage of disease and recurrence. 